\title{
Home, Land and Sea: Situating music in Aotearoa New Zealand
}

\author{
Glenda Keam and Tony Mitchell, ed \\ Auckland: Pearson Education Australia, 2011 \\ ISBN: 978-1-4425-632-8 (PB)
}

\author{
Roy Shuker \\ Victoria University of Wellington \\ roy.shuker@vuw.ac.nz
}

This collection seeks to move discussion further away from what is seen as a preoccupation with a 'nationally distributed musical identity' in earlier academic discussion of 'New Zealand music', with the associated issues that such focus brings (see Johnson, 2010). Instead, the editors argue that "there is increasingly comprehensive and conclusive evidence of a wide range of regionally situated local musics in New Zealand" and that:

evident in all genres of music in the country, from art music to hip hop, are traces of landscapes and 'sonic geography', whether urban or rural. These are not necessarily related to expressions of national identity, but rather to a more locally grounded poetics of home and belonging, and in some cases a sense of alienation (x).

Accordingly, the emphasis is very much on music in terms of place. The great majority of the chapters are original essays, written exclusively for the collection, with their authors bringing a refreshingly diverse range of methodologies, critical and creative perspectives to their topics.

There are five parts. The first, on Taonga Puoro, Pasifikan Descendants and Reggae, foregrounds the indigenous and Pacific Islander musical heritage. Tony Mitchell and Tama Waipara provide a useful historical sketch of developments in Maori music, including the show bands of the 50s and $60 \mathrm{~s}$, the revival of traditional instruments, and the institutionalization of Maori music awards. Further chapters consider the fusion of the local and international musical traditions such as R\&B, gospel and reggae, with Jennifer Cattermole's chapter on the localisation of roots reggae particularly instructive on how this process of hybridization occurs.

In section 2: Music and New Zealand cultural identities, there are insightful discussions of the manner in which iconic New Zealand songs are used at rugby matches; the increased visibility of 'migrant music'; and how local hip hop artists reflect a complex series of cultural alignments and trajectories.

The case studies in Parts 2 and 3 provide something of a mixed bag. Tony Mitchell, writing on Auckland and Christchurch, illustrates the strengths and limitations of a form of ethnographic recovery - his sonic geographies. On the one hand, there is a fascinating richness of detail here, but it is at times thrown together with little attempt to 
distinguish the relative importance of particular events, locations, persons, and musical texts. On the other hand, several chapters on Wellington draw on extensive interviews along with participant observation to provide more of a nuanced insight into the constitution and operation of local scenes. In what was for me a standout piece, Geoff Stahl shows how indie rock musicians operate in a different musical space from that created by the more visible State subsidy schemes, which they seek to actively distance themselves. Other chapters consider the community politics which are central to the annual Cuba Street Carnival; the much-praised Wellington jazz-dub-reggae musical style; the House music scene in Dunedin, especially the role of the DJ; and the nature and impact of South Island-based DIY (do it yourself) record labels, emphasising the role of technology and its cohabitation with aesthetics.

Part 5, on 'Art Music, Landscapes of Listening and Experimental Soundscapes' provides some very useful discussions of the development of music rarely considered within 'mainstream' local academic examinations of music making in New Zealand. These include analyses of the precarious position of experimental music and post punk musicians; 'art music' in relation to compositional practices, sounds, and their sense of place; how electroacoustic music has historically developed within the New Zealand tradition of DIY (do it yourself) culture; and the innovative use of unconventional instruments by pioneers such as Len Lye and current composers and musicians.

At times, there is a lack of clear definition of the spatial concepts evoked, and an editorial conclusion demonstrating the communalities of the various contributions would have been helpful. Instead, in what is presumably an attempt to appeal to a broader readership, there is an afterword by prominent local musician Don McGlashan, who concludes:

there is cause to celebrate in the fact that New Zealand music in all its many and varied forms now resonates with new generations of New Zealanders, who listen to it, support it and argue about it, not out of a sense of patriotic obligation, but because it matters to them (281).

The editorial introduction approvingly cites John Street's definition of the relationships between music and locality in terms of industrial base, social experience, aesthetic perspective, political experience, community and scene $(x)$. But it is social experience that is foregrounded here; rarely do we see much in the way of considerations of political economy. A crucial absence is any informed and sustained consideration of the role of government policy in facilitating the localized production of music and associated expressions of place. This appears to reflect the editors' distrust of the manner in which notions of 'New Zealand' identity have been adopted by Government to justify support for the media culture and the arts.

Co-editor Mitchell argues, yet again, that State intervention is not a significant factor behind the viability and vitality of local music. In the space of a page (xx) in the introduction, Mitchell manages to include misrepresentation, selected evidence, and a limited argument. Elsewhere, I have extensively argued that:

Governmental willingness to get behind New Zealand music has contributed to the present success of both the mainstream commercial and the indie sectors, primarily by creating a changed musical climate that has ensured the greater visibility of 'the local' generally (Shuker, 2008: 282-3; my emphasis).

Mitchell quotes this passage, in order to contest it, but in the process ingeniously renders 'contributed to' as 'largely due' (my emphasis), and shows a surprising ignorance of the local Government schemes. He simplistically equates government support with direct funding and even then only includes NZOA, ignoring the major contribution of the New Zealand Music Commission.

In support of his view, Mitchell cites examples of bands such as Fat Freddy's Drop and So So Modern whom he considers to have achieved local success without support from NZOA. While this is certainly accurate, and is supported by Stahl's chapter on 
Wellington indie, it misses the point that all performers are making music within the same wider economic context. Mitchell also conveniently overlooks the success of other performers supported by the schemes, with the great majority of top selling New Zealand artists receiving some form of State support. Further, he seems unaware of the comprehensive review of the NZOA schemes, undertaken in 2010 by former EMI music head Chris Caddick, who interviewed a hundred 'music and broadcast professionals' and also assessed the 655 responses from a public survey. While recognising the scheme had its problems, primarily its emphasis on commercial radio and its lack of attention to new media for discovering, consuming and sharing music, Caddick concluded that:

While industry or artist support is not a primary goal, the stability inherent in NZ On Air's music programme has nonetheless provided strong support for the New Zealand music industry. As a consequence an industry infrastructure has been strengthened and an ever-increasing pool of new artists aspires to create music and have it heard by their fellow countrymen (2010: 4).

NZOA quickly responded to the Review, making a number of changes to the schemes. I have rather laboured this point as it seems it is not only a key absence but one illustrative of a more general problem with a straightforward emphasis on place and immediate locality.

Many contributors here are at pains to tell the reader what 'New Zealand music' is or is not; and continue to draw on ideologically constructed binaries such as alternative not mainstream/commercial. The result is a privileging of certain styles of local music and their performers; these certainly document a musical breadth but also result in some significant omissions. In discussions of Christchurch and Auckland for example, there is no reference to Haley Westrena or Bic Runga, presumably because these 'commercial' performers are not ideologically acceptable to Mitchell's 'countercartography'.

Such absences aside, Home, Land and Sea is deservedly set to become the 'standard' course reader on music in Aotearoa New Zealand.

\section{References}

Caddick, C. (2010) Review of New Zealand On Air's Domestic Music Promotion \& Funding Schemes. NZ on Air. www.nzonair.govt.nz Accessed: 10 Feb. 2014

Johnson, H. ed. (2010) Many Voices: Music and National Identity in Aotearoa/New Zealand. Cambridge Scholars Publishing: Newcastle upon Tyne.

Shuker, R. (2008) "New Zealand popular music, government policy, and cultural identity". Popular Music 27(2): 271-287. 